\title{
Barriers to Parental Involvement in the Education of Learners with Intellectual Disabilities
}

\author{
Josephine Oranga $₫$, Enock Obuba $₫$, Florence J. Boinett \\ Kisii University, Kenya \\ Email: josephineoranga@kisiiuniversity.ac.ke, enockobuba@kisiiuniersity.ac.ke, fboinnet@kisiiuniversity.ac.ke
}

How to cite this paper: Oranga, J., Obuba, E., \& Boinnet, F. J. (2022). Barriers to Parental Involvement in the Education of Learners with Intellectual Disabilities. Open Journal of Social Sciences, 10, 410-423.

https://doi.org/10.4236/jss.2022.102029

Received: January 10, 2022

Accepted: February 25, 2022

Published: February 28, 2022

Copyright $\odot 2022$ by author(s) and Scientific Research Publishing Inc. This work is licensed under the Creative Commons Attribution International License (CC BY 4.0).

http://creativecommons.org/licenses/by/4.0/

\begin{abstract}
This study is an in-depth qualitative literature review on the barriers to parental involvement in the education of learners with intellectual disabilities. The review adopted Paulo Freire's theory in an attempt to illustrate the significant role that parents are supposed to play in the education of their children with intellectual disabilities. The findings revealed that the barriers to enhanced parental involvement in the education of learners with intellectual disabilities include: low level of parental education, teachers' negative attitude towards both the affected learners and their parents, economic constraints, stigmatization of intellectual disabilities, lack of support, parental stress/depression, lack of knowledge and skills, the number of siblings in the family, mismatched expectations (between parents and teachers), absence of legal/policy frameworks on parental involvement, absence of clear channels of communication between parents and school personnel and, the severity of the child's disability. As a result of the findings, some suggestions to enhance parental involvement in the education of learners with intellectual disabilities are given, these include: parental education, economic emancipation of the parents, change of teachers' attitude, specialized training for all persons handling learners with intellectual disability, establishment of positive home-school working relationships, proper legislation on handling people with disabilities, civic education on human rights and development of a policy framework to guide school-home collaborations.
\end{abstract}

\section{Keywords}

Barriers, Strategies of Intervention, Parental Education, Intellectual Disabilities, Special Needs Education 


\section{Introduction}

Studies (Stevenson \& Baker, 1987; Rudney, 2005; Blacher \& Hatton, 2007) reveal that children whose parents are more involved in school activities (like joining parent-teacher organizations, attending parent-teacher conferences and volunteering) perform better in school than those whose parents are less involved. Additionally, other studies (Steinberg, 2009; Rudney, 2005) detail that parental involvement, encouragement, and positive reinforcement are linked to children's academic competence, a strong feeling of self-worth, positive social relations and fewer behavioural problems. Moreover, studies reveal that parental involvement in the education of children with disabilities besides helping improve their performance also creates a motivating learning environment that is a prerequisite for enhanced educational outcomes for learners with intellectual disabilities.

Studies also reveal that parental involvement helps cultivate a good relationship between parents and teachers and builds a more suitable school environment in favour of children (Hornby \& Lafaele, 2011). Accordingly, parents are the first and most important teachers that children encounter and thus, their involvement in their children's education would accelerate and simplify learning, ultimately resulting in improved educational outcomes (Moroni et al., 2015).

Furthermore, findings from a growing number of studies (Banerjee, Harrell, \& Johnson, 2011; Fantuzzo et al., 2004; Powell, 2010; Oranga, Obuba, \& Nyakundi, 2020) suggest a positive impact of parental involvement on preschool children's emerging literacy skills, including receptive and expressive vocabulary, auditory processing, identifying rhyming words, segmentation of words, knowledge of print, and pre-writing skills.

Moreover, parents' advocacy has been shown to improve children's academic outcomes (Henderson et al., 2007). Accordingly, parental participation in school activities enhanced parent-teacher communication resulting in cooperation between parents and teachers ultimately resulting in enhanced educational outcomes.

Other studies indicate that some educational institutions have recognized the importance of parental involvement and are researching ways of supporting and engaging with parents more (Stalker et al., 2011, Ruskus \& Gerulaitis, 2010). For instance, "parent involvement and participation" was described in the $2000 \mathrm{Na}$ tional Education Target by the White House in the United States of America, stressing that every school strengthens parental involvement in order to improve and enhance the partnership between family and school.

On the other hand in the United Kingdom, the government requires schools to discuss and document their teaching objectives, education responsibilities and learning expectations from students in full collaboration with the parents (Stalker et al., 2011; Hornby \& Lafaele, 2011). This, thus, emphasizes the importance of parental involvement in education, and even more so, in the education of children with intellectual disabilities who require consistent and perpetual atten- 
tion from both parents and teachers in order to benefit from schooling.

Ruskus \& Gerulaitis (2010) and Holte et al. (2014) assert that parental involvement is vital and that parenting has exceptional characteristics which distinguish it from all other roles that people fulfill in adulthood. Consequently, one prominent quality is that it involves unique intensive interpersonal relationship, commitment, responsibility, emotional and practical nurturing. Accordingly, the importance of this role and its social expectations render it impossible for parents to relinquish or suspend this responsibility. This becomes even more imperative when children involved are exceptional that is, those with intellectual disability.

\section{Statement of the Problem}

A number of studies (Moroni et al., 2015; Mendez \& Lloyd 2005; Reinke et al., 2011) suggest that parents are not playing their rightful role in the education of their children, and even more so those with intellectual disabilities.

Involvement in education has been linked to improved academic outcomes amongst learners of all ages, and even more so, those with disabilities (Hornby \& Lafaele, 2011; Bjorgvinsdottir \& Halldorsdottir, 2014). The purpose of this literature review analysis was to establish the reasons behind the low state of parental involvement in education, with a special focus on learners with intellectual disabilities, with a view to determining strategies of surmounting the barriers and challenges encountered by the parents in their attempt to participate in their children's education.

This paper thus, strives to examine the relatively sparse literature on barriers to parental involvement in the education of learners with intellectual disabilities and ultimately provides suggestions and recommendations for surmounting them.

\section{Methodology}

Thematic interpretations and understandings of the barriers to parental involvement in the education of learners with intellectual disabilities were arrived at after an in-depth review of relevant literature. Documents, web databases, journals and institutional websites were scoured to gather information that is relevant to this analysis. This paper thus, presents the barriers to parental involvement in the education of learners with intellectual disabilities and provides suggestions and recommendations for navigating the obstacles.

\section{Theoretical Framework}

This analysis borrows immensely from Paulo Freire's theory of emancipation. Freire (1971) examines the struggle for equity and fairness within the education system and proposes a new pedagogy that focuses on social justice, equity and fairness with regard to race, gender, disability class and/or sexual orientation. Accordingly, this can only be achieved through an education system that creates 
a partnership between the student, teacher and parent with the aim of empowering the student and in this case, students with intellectual disabilities. The theory is concerned with the disadvantaged and those that suffer and fight alongside them, and in this case, learners with intellectual disabilities and their parents.

According to the theory, parents have a vital role to play in their children's education and in bringing about the desired change in education systems. Accordingly, the quest for change in schools and classrooms must be pursued responsibly and constantly as success will be the result of praxis (informed action) when a balance between practice and theory is achieved.

Moreover, student-teacher and parent-teacher relationships are vital, as are access to resources and information to all students including those with disabilities. Freire (1971) maintains that teachers should bear in mind the diverse backgrounds and nature of students under their care, further indicating that a monocultural framework cannot address all students' challenges.

Within this framework, this study sought to bring to the fore the barriers that hinder parental involvement in the education of learners with intellectual disabilities. Of special focus were the ways through which these barriers can be surmounted to the advantage of learners with intellectual disabilities.

In line with Freire (1971), parents should therefore be supported and enlightened on the importance of involvement in their children's education in order for them to play their rightful role, thereby, resulting in the envisaged education system that is fair, just and equitable for all regardless of whether or not they have a disability.

\section{Barriers to Parental Involvement in Education of Learners with Intellectual Disabilities}

Various studies explain the reasons for under participation in schools by parents of learners with disabilities. The studies (Ruskus \& Gerulaitis, 2010; Blacher \& Hatton 2007; Bjorgvinsdottir \& Halldorsdottir, 2014) contend that lack of information or knowledge hinders parents in their attempt to participate in their children's education effectively. Consequently, the lack of knowledge on nature and prognosis of a child's disability also holds back parents from implementing professional and educational suggestions at home ultimately impacting the children's general growth and academic outcomes.

Similarly, studies (Chevalier et al., 2013; Hoover-Dempsey et al., 2007) indicate that a parent's attained level of education may hinder in-depth understanding of their child's disability and render them unable to help the children at home as ideally, parents should play the important role of ensuring continuity and practice, at home, of the academic, social and adaptive skills that children (with intellectual disabilities) learn at school. Their involvement in the education of their children with intellectual disabilities is thus, imperative.

In the same breadth, studies show that low levels of parental education, hinder 
parents' involvement in their children's education. Consequently, parental level of education would also determine the degree and level of involvement. Accordingly, parents who have higher education levels are more involved in the education of their children with intellectual disabilities as compared to those with lower levels of education (Feliciano, 2006; Englund et al., 2004; Anderson \& Minke, 2007).

The studies also reveal that parents with lower levels of education experience more challenges with regard to their children's schooling than the educated middle class ones. Apparently, educated parents may handle a child with disabilities better and help them at home than their counterparts without education. Hence there is need to enlighten, educate and support parents with low educational levels in an effort to offer a fair and just education to all as envisaged by Freire (1971).

Similarly, studies (Chevalier et al., 2013; Anderson \& Minke, 2007; Boult, 2006) contend that there is a positive relationship between parental involvement in their children's schooling, their level of income and their level of education. The study observes that low parental level in education, not only denies them knowledge of raising children, but also leads them to low paying jobs, requiring them to work more hours. Accordingly, such parents also tend to have many children, requiring more commitment. This situation impacts learners with disabilities and even more so, those with intellectual disabilities negatively as they require more help and attention from their parents than regularly growing children. The study, thus, recommended policy intervention, like subsiding the low income, low education level parental training, and high level policy on how persons with intellectual disabilities should be treated in society.

A study by Decastro-Ambrosetti and Cho (2005) in the US on a sample of 15 parents revealed that parents with too many commitments or many children that need attention might not have enough time to successfully participate in parental programmes for their child with disabilities. Accordingly, working parents too, may not participate to a full extent as parents must divide their attention between work and the children. Hence, necessitating the need for schools to devise ways to involve working parents and those with myriad commitments by having an open dialogue with them and explaining the benefits of parental involvement in education and most importantly, in the education of learners with intellectual disabilities.

Besides, the findings also revealed that teacher factors also form a barrier to full parental involvement in education. Accordingly, the teacher factors include; teachers' negative attitude towards parents (for example perceiving parents as a threat or challenge and failing to regard parents as valuable resources), dismissing parental observations as being biased or negligible, conflicts between school directors or board of management members, lack of funds, unresolved emotional feelings and lack of teacher training on how to work with parents (Ruskus \& Gerulaitis, 2010, Feliciano, 2006). 
Similarly, Stewart (2008) and Lopez (2001) observed that lack of in-service training of teachers on parental involvement forms a barrier to parental involvement as the teachers may not know how to effectively collaborate and engage with parents from the basic pre-service training they received, thus necessitating specified in service train for them.

Moreover, studies (Dempsey, Walker, \& Reed, 2002; Chevalier et al., 2013) echo the same sentiments and detail that despite the considerable amount of theoretical and empirical work supporting the critical role of parents in students' school success, pre-service teachers generally receive little training and preparation for involving and engaging parents, thereby, justifying the need for continuous training of teachers on "engaging or working with parents".

Mugo, Oranga, and Singal (2010) and Stormshak et al. (2005), on the other hand observes that the most significant barrier is that most teachers and other school professionals are trained in an individual-cantered model of service delivery which rarely incorporates parents. Additionally, school professional implement a narrow, rigid educational plan that is unable to support the needs of parents, consequently increasing the likelihood of low participation and lack of engagement with parents. This often results in parents reporting feelings of powerlessness, frustration, and marginalization from teachers and the schooling process (Moore \& Lasky, 1999).

Other studies (Winslow et al., 2013; Weiss et al., 2003) reveal that parental lack of information or understanding regarding the structure of the school and accepted channels of communication and feeling unwelcomed by teachers and other school personnel also hinder parental participation in their children's education and more especially those with intellectual disabilities, hence calling for a change of attitude towards parents by all the school personnel in general.

Reinke et al. (2011) observe that aspects of the school environment, including biases and negative perceptions of parents are also unwelcoming to parents. Accordingly, parents may also hold the opinion that health intervention on their children with disabilities may fall outside the school roles (Reinke et al., 2011), thus, holding back their participation in their child's health interventions conducted at school. Hence, an understanding on why and where such interventions should be conducted should be determined and reached amicably in order to encourage full support and participation from the parents.

Consequently, a quantitative research conducted by Mendez and Lloyd (2005), in Mexico, concludes that both parents and teachers experience common barriers to parental involvement, such as limited knowledge and skills about parent-teacher engagement, restricted opportunities for cooperation and psychological and cultural barriers (Mendez \& Lloyd, 2005). Given these barriers, many schools and families never realize the benefits of parental involvement. Instead, dissatisfaction, frustration and even hostility mark the relationship between parents and school. This calls for support and training for both teachers and parents on how to collaborate for the benefit of learners with disabilities under their care. 
Similarly, Deslandes and Bertrand (2005), report that one of the reasons parents choose not to participate in their children's education is uncertainty and lack of knowledge about their role(s). Accordingly, most parents are usually unsure of what teachers and schools expect of them. The studies recommend parental training through workshops and seminars as one of the ways through which parents can become knowledgeable about their roles and responsibilities in their children's education.

McKay et al. (2004), also states that structural, contextual, cultural, and perceptual barriers interfere with sustained participation of parents in the education of their children. They further classify the barriers as: economic constraints, severity of a child's disability, parental stress/depression levels, lack of support, lack of knowledge and skills, and lack of confidence. In addition, parents' perceptions of the teachers and school staff, mismatched expectations all determine whether or not parents will persist in seeking services and cooperating with the school for the sake of their children (McKay et al., 2004; Feliciano, 2006, Englund et al., 2004). Accordingly, structural barriers and obstacles such as limited services, transportation, insurance, childcare, and time become depressing barriers to parental participation in education.

Sandall et al. (2005) reiterate that in reality parents of learners with disabilities occupy a low and less favourable position in the educational enterprise yet educationists portray the teachers and parents as equal partners, consequently, the low position occupied by parents' acts as a barrier to their involvement in their children's education. Accordingly, some parents perceive teachers as professionals in authority trained in handling all school matters, so they leave their children to the full responsibility of teachers. Even so, the teachers occasionally act so, giving parents instructions, instead of getting them to cooperate and collaborate with them.

On the other hand, research also reveals that most parents of children with disabilities, including those with intellectual disabilities are extremely poor and are incapable of meeting the educational needs of their children, resulting in parental lack of concern for their children's education. Accordingly, just a handful of children with disabilities have the advantage of an appropriate education in developing countries (Pang \& Richey, 2005). This is attributed to the poor state of health, nutrition and general livelihood in low-income countries (Chevalier et al., 2013).

Additionally, Vaden-Kiernan et al. (2005), report that a family's socio-economic status (SES), will determine whether the parents will participate in their children's education with families with fewer economic resources tending to have lower levels of parental involvement. Subsequently, children who grow up in poverty are at high risk for negative outcomes such as lower levels of academic achievement and socio-emotional well-being due to lack of parental involvement (Oranga \& Chege Kabutha, 2013; Allhusen, 2005).

Similarly, Smalley and Reyes-Blanes (2001), blame lack of financial resources by parents as a barrier to parental participation in education. According to the 
authors, involving parents in low-income communities, in their children's education remains one of educators' greatest challenges. It is likely that parents who lack the resources to help their children academically may have more difficulty in assisting their children with academic success. This also explains why past studies revealed that parents of higher socioeconomic status (SES) are more involved in their children's education.

In addition, lack of time and energy, embarrassment and shyness regarding the parent's own level of education and verbal abilities were also established as barriers to parental involvement in their children's education (Decastro-Ambrosetti \& Cho, 2005; Stewart, 2008; Lopez, 2001). Accordingly, parental education may go a long way in instilling confidence in the parents and enlightening them on the significant role they must play in their children's education.

On the other hand, lack of policies and legal frameworks in developing countries within which parents of children with disabilities can advocate for the rights of their children was also cited as a barrier to parental involvement in the education of their children with disabilities in Africa. Accordingly, this has resulted in the provision of inadequate services for persons and learners with disabilities (Wood, Ross-Kerr, \& Brink, 2006; Wright, 2009). This becomes even more detrimental for learners with intellectual disabilities

Mutua and Dimitrov (2001) also report that laws protecting persons with disabilities and their families are non-existent in most African countries. Subsequently, there is no concrete mechanism for fighting stigma, resulting in a lack of social acceptance and challenges in accessing education and other services by persons with disabilities, consequently, leading to neglect and abandonment of learners with disabilities and their families. Accordingly, laws that aim to educate society on disabilities and inclusivity would go a long way in helping eliminate stigma and encourage acceptance, responsiveness and sensitivity to the needs of persons and learners with disabilities by families and society at large.

Furthermore, Korir, Mukuria and Andera (2007), report that practices of discrimination and inequality pertaining to individuals with disabilities are imbedded in the African culture and perpetuated in family, community, and society at large. Further, individuals with intellectual disabilities are placed at the bottom of the ladder as far as social status is concerned. Consequently, persons with intellectual disabilities in most African countries are subjected to discrimination ultimately resulting in the lack of parental involvement in their education. The authors observe that persons with intellectual disabilities have little or no access to education, health, employment, and rehabilitation in the vast majority of African countries, thereby perpetuating the vicious cycle of poverty amongst persons with intellectual debilities, generally (Mutisya, Oketch, \& Sagwe, 2012).

On the other hand, authors (Rillotta et al., 2020; Reinke, 2013), contend that children with intellectual disabilities should be handled in such a manner that they are able to develop in four main thematic areas in order for them to be productive and successful in society, the areas are: self-determination (self-confidence), social 
development (social networks), intellectual development (subject knowledge) and inclusive practices. Accordingly, this calls for enhanced parental enlightenment and participation in their education.

However, according to the authors, the children are usually already negatively socialized from home, at school and in the society. Oftentimes, they are considered and treated as having deficiencies in capacity to develop essential capabilities and skills. This, thus, informs the educational decisions that parents in these communities make for their children with intellectual disabilities, subsequently, forming a barrier to their involvement in the children's education.

Rillotta et al., (2020) recommend better perception and treatment of persons with intellectual disabilities by society in general, but even more so, the school-going ones in order for them to develop in areas that make them self-reliant, confident and sociable among other thematic areas for them to develop certain capabilities, thus requiring enhanced participation of their parents in their education.

Further, Kenyan studies on assessment and placement of learners with disabilities report that the education of individuals with disabilities is faced with myriad challenges. These challenges include: assessment of the disability, identification and referral process, educational placement, parents' involvement and training, individualization of instruction and funding (Mumia, 2014; Robert \& Kaiser, 2011; Oranga, Obuba, \& Sore, 2020). Moreover, the authors observe that learners with intellectual disability have remote chances of going beyond elementary schools, getting employment or receiving vocational education, underscoring the importance of parental enlightenment, emancipation and participation (Freire, 1971) in order to help bring about the desired change for children with intellectual disabilities as happened in the West during the grassroots beginnings of special needs education.

Unfortunately, lack of parental enlightenment and emancipation and other reasons as discussed above have served as formidable barriers to the full participation of parents of learners with disabilities in schools worldwide but most especially in developing countries. This, thus, calls for urgent redress measures for the benefit of all learners, and even more so, those with intellectual disabilities.

\section{Conclusion}

The findings reveal that the barriers to parental involvement in the education of learners with intellectual disabilities are diverse and include: low level of parental education, teachers' negative attitude towards parental participation in education, parental economic constraints, societal perceptions and stigmatization of intellectual disabilities, lack of knowledge of prognosis of intellectual disabilities, parental stress and depression, lack of support, parental perceptions of the teachers-school staff, absence of clear channels of home-school communication, mismatched expectations (between parents and teachers), the number of siblings in the family, severity of the child's disability, differences in language between 
school staff and parents and absence of policy guidelines/framework that would guide parental involvement in education.

Additionally, the absence of concrete efforts towards inclusion and a total lack of programmed in-service seminars for teachers handling learners with intellectual disabilities also emerged as hindrances to parental involvement in the education of learners with intellectual disabilities. As revealed in the discussion, parents would get more involved in their children's education if they felt knowledgeable and capable, and if their participation was encouraged by teachers, hence the need to empower parents as advocated for by Paulo Freire (1971).

\section{Recommendations}

In response to the various barriers to parental involvement as revealed by this analysis, the following recommendations are given in an attempt to address the apparent low level of parental involvement in education and more importantly in the education of learners with intellectual disabilities: Provision of parental education and training through workshops and seminars, economic emancipation of parents through government subsidies and welfare cash transfers, educating communities about disabilities in a bid to eliminate stigmatization of persons with intellectual disabilities, help with job placements for skilled/semi-skilled and educated parents, modification of teachers' attitudes towards parental participation in education, training teachers on "working with parents", establishment of home-school working mechanisms by the schools and the development of school-home collaboration policy framework by stakeholders in the Ministry of Education.

It was envisaged that regular workshops and in-service of teachers handling learners with intellectual disabilities would help highlight the significance of parental participation in their children's education, thereby enlightening and compelling teachers to determine ways of supporting and bringing parents on board more often.

Additionally, schools should strive to strike a chord with the parents and create a welcoming and empathetic atmosphere. Furthermore, teachers should be compassionate and understanding towards parents with low educational levels and strive to create an atmosphere that is welcoming to all. Moreover, parents should be encouraged to voice concerns, opinions and questions without the fear of being judged inferior.

Conclusively, parents should be supported and enlightened on the importance of involvement in their children's education in order for them to play their rightful role, ultimately, resulting in the envisioned education system that is fair and just to all learners regardless of whether or not they have a disability.

\section{Conflicts of Interest}

The authors declare no conflicts of interest regarding the publication of this paper. 


\section{References}

Allhusen, V. D. (2005). Nonparental Caregiving. In M. H. Bornstein (Ed.), Handbook of Parenting: Volume 3. Being and Becoming a Parent. Psychology Press.

Anderson, K., \& Minke, K. (2007). Parent Involvement in Education: Toward an Understanding of Parents' Decision Making. The Journal of Educational Research, 100, 311-323. https://doi.org/10.3200/JOER.100.5.311-323

Banerjee, M., Harrell, Z. A., \& Johnson, D. J. (2011). Racial/Ethnic Socialization and Parental Involvement in Education as Predictors of Cognitive Ability and Achievement in African American Children. Journal of Youth and Adolescence, 40, 595-605. https://doi.org/10.1007/s10964-010-9559-9

Bjorgvinsdottir, K., \& Halldorsdottir, S. (2014). Silent, Invisible and Unacknowledged: Experiences of Young Caregivers of Single Parents Diagnosed with Multiple Sclerosis. Scandinavian Journal of Caring Sciences, 28, 38-48. https://doi.org/10.1111/scs.12030

Blacher, J., \& Hatton, C. (2007). Families in Context. In S. Odom, R. Horner, M. Snell, \& J. Blacher (Eds.), Handbook on Developmental Disabilities (pp. 531-551). The Guilford Press.

Boult, B. (2006). 176 Ways to Involve Parents: Practical Strategies for Partnering with Families. Thousand Oaks: Corwin Press.

Chevalier, A., Harmon, C., O’Sullivan, V., \& Walker, I. (2013). The Impact of Parental Income and Education on the Schooling of Children. IZA Journal of Labor Economics, 2, Article No. 8. https://doi.org/10.1186/2193-8997-2-8

DeCastro-Ambrosetti, D., \& Cho, G. (2005). Do Parents Value Education? Teachers' Perceptions of Minority Parents. Multicultural Education, 13, 44-46.

Dempsey, K. V., Walker, M. T., Jones, P., \& Reed, R. (2002). Teachers Involving Parents (TIP): Results of an In-Service Teacher Education Program for Enhancing Parental Involvement. Teaching and Teacher Education, 18, 843-867. https://doi.org/10.1016/S0742-051X(02)00047-1

Deslandes, R., \& Bertrand, R. (2005). Motivation of Parent Involvement in Secondary Level Schooling. The Journal of Educational Research, 98, 164-175.

https://doi.org/10.3200/JOER.98.3.164-175

Englund, M. M., Luckner, A. E., Whaley, G. J., \& Egeland, B. (2004). Children's Achievement in Early Elementary School: Longitudinal Effects of Parental Involvement, Expectations, and Quality of Assistance. Journal of Educational Psychology, 96, 723-725. https://doi.org/10.1037/0022-0663.96.4.723

Fantuzzo, J., McWayne, C., Perry, M. A., \& Childs, S. (2004). Multiple Dimensions of Family Involvement and Their Relations to Behavioral and Learning Competencies for Urban, Low-Income Children. School Psychology Review, 33, 467-480.

https://doi.org/10.1080/02796015.2004.12086262

Feliciano, G. M. (2006). Multiple Exemplar Instruction and the Listener Half of Naming in Children with Limited Speaker Abilities. Columbia University.

Freire, P. (1971). The Pedagogy of the Oppressed. The Penguin Books.

Henderson, A. T., Mapp, K. L., Johnson, V. R., \& Davies, D. (2007). Beyond the Bake Sale: The Essential Guide to Family-School Partnerships. The New Press.

Holte, A., Barry, M., Bekkhus, M., \& Trommsdorff, G. (2014). Psychology of Child Well-Being (pp. 555-631). Dordrecht: Springer Press.

https://doi.org/10.1007/978-90-481-9063-8 13

Hoover-Dempsey, K. V., Green, C. L., Walker, J. M., \& Sandler, H. M. (2007). Parents' 
Motivations for Involvement in Children's Education: An Empirical Test of a Theoretical Model of Parental Involvement. Journal of Educational Psychology, 99, 532-534. https://doi.org/10.1037/0022-0663.99.3.532

Hornby, G., \& Lafaele, R. (2011). Barriers to Parental Involvement in Education: An Explanatory Model. Educational Review, 63, 37-52.

https://doi.org/10.1080/00131911.2010.488049

Korir, B., Mukuria, G., \& Andrea, B. (2007). Educating Children with Emotional and/or Behavioral Disorders in Kenya: A right or a Privilege? Journal of International Special Education, 10, 49-57.

Lopez, G. (2001). The Value of Hard Work: Lessons on Parent Involvement from an (Im)migrant Household. Harvard Educational Review, 71, 416-438. https://doi.org/10.17763/haer.71.3.43x7k542x023767u

McKay, M. M., Hibbert, R., Hoagwood, K., Rodriguez, J., Murray, L., Legerski, J., \& Fernandez, D. (2004). Integrating Evidence-Based Engagement Interventions into "Real World" Child Mental Health Settings. Brief Treatment \& Crisis Intervention, 4, 177-186. https://doi.org/10.1093/brief-treatment/mhh014

Mendez, J. L., \& Lloyd, B. T. (2005). Resilient Partners: The Development of a University-Community Collaboration to Promote Wellness for Head Start Children and Families. National Head Start Association Dialog, 8, 36-55.

https://doi.org/10.1207/s19309325nhsa0801 6

Moore, S., \& Lasky, S. (1999). Parents Involvement in Education: Models, Strategies and Contexts. Building Bridges between Home and School, 9, 13-18.

Moroni, S., Dumont, H., Trautwein, U., Niggli, A., \& Baeriswyl, F. (2015). The Need to Distinguish between Quantity and Quality in Research on Parental Involvement: The Example of Parental Help with Homework. The Journal of Educational Research, 108, 417-431. https://doi.org/10.1080/00220671.2014.901283

Mugo, K. J., Oanga, J., \& Singal, N. (2010). Testing Youth Transitions in Kenya: Are Young People with Disabilities Falling through the Cracks? RECOUP Working Paper No. 34.

https://www.dfid.gov.uk/R4D/PDF/Outputs/ImpOutcomes_RPC/WP34-JKM.pdf

Mumia, B. J. (2014). The Relationship between Intellectual Capital and Financial Performance of Companies Listed in the Nairobi Securities Exchange. Doctoral Dissertation, University of Nairobi.

Mutisya, M., Oketch, M., \& Sagwe, J. (2012). Parental Aspirations for Their Children's Educational Attainment and the Realisation of Universal Primary Education (UPE) in Kenya: Evidence from Slum and Non-Slum Residences. International Journal of Educational Development, 32, 764-772. https://doi.org/10.1016/j.ijedudev.2011.04.002

Mutua, K., \& Dimitrov, D. M. (2001). Prediction of School Enrolment of Children with Intellectual Disabilities in Kenya: The Role of Parents' Expectations, Beliefs \& Education. International Journal of Disability, 48, 179-191.

https://doi.org/10.1080/10349120120053658

Oranga, J. N., Chege, F., \& Kabutha, M. J. (2013). Success among Blind Students in Kenya: The Case of Kenyatta University. Journal of Special Needs and Disability Studies, 1, 77-88.

Oranga, J., Obuba, E., \& Nyakundi, E. (2020). Education as an Instrument of Poverty Eradication in Kenya: Successes and Challenges. Open Journal of Social Sciences, 8, 410-424. https://doi.org/10.4236/jss.2020.89031

Oranga, J., Obuba, E., \& Sore, I. (2020). Parental Involvement in Education of Learners with Intellectual Disabilities in Kenya. Journal of Research Innovation and Implica- 
tions in Education, 4, 67-78.

Pang, Y., \& Richey, D. (2005). A Comparative Study of Early Intervention in Zimbabwe, Poland, China, India, and the United States of America. International Journal of Special Education, 20, 122-131.

Powell, S. M. D. (2010). The Effect of Parental Involvement on Mathematics Achievement of African American Middle School Students. Doctoral Dissertation, Walden University.

Reinke, W. M. (2013). Integrating Effective Family and School Interventions: Initial Findings and Implications. Manuscript Submitted for Publication.

Reinke, W. M., Stormont, M., Herman, K. C., Puri, R., \& Goel, N. (2011). Supporting Children's Mental Health in Schools: Teacher Perceptions of Needs, Roles, and Barriers. School Psychology Quarterly, 26, 1-13. https://doi.org/10.1037/a0022714

Rillotta, F., Arthur, J., Hutchinson, C., \& Raghavendra, P. (2020). Inclusive University Experience in Australia: Perspectives of Students with Intellectual Disability and Their Mentors. Journal of Intellectual Disabilities, 24, 102-117. https://doi.org/10.1177/1744629518769421

Robert, J., \& Kaiser, K. (2011). The Effectiveness of Parent-Implemented Language Interventions: A Meta-Analysis. American Journal of Speech-Language Pathology, 20, 180-199. https://doi.org/10.1044/1058-0360(2011/10-0055)

Rudney, G. (2005). Every Teacher's Guide to Working with Parents. Thousand Oaks: Corwin Press.

Ruskus, J., \& Gerulaitis, D. (2010). Parental Involvement in Individual Education Planning for Students with Mental Disabilities: A Lithuanian Experience. Illinois child Welfare: A Multidisciplinary Journal Dedicated to Improving Services for Children and Their Families. Chicago: Loyola University Chicago, School of Social Work.

Sandall, S. R., McLean, M., Santos, R. M., \& Smith, B. J. (2005). DEC’s Recommended Practices: The Context for Change. In S. Sandall, M. L. Hemmeter, B. J. Smith, \& M. E. McLean (Eds.), DEC Recommended Practices: A Comprehensive Guide for Practical Application in Early Intervention/Early Childhood Special Education (pp. 19-39). Sopris West.

Smalley, S. Y., \& Reyes-Blanes, M. E. (2001). Reaching out to African American Parents in an Urban Community: A Community-University Partnership. Urban Education, 36, 518-533. https://doi.org/10.1177/0042085901364005

Stalker, K. O., Brunner, R., Maguire, R., \& Mitchell, J. (2011). Tackling the Barriers to Disabled Parents' Involvement in their Children's Education. Educational Review, 63, 233-250. https://doi.org/10.1080/00131911.2010.537313

Steinberg, L. (2009). Should the Science of Adolescent Brain Development Inform Public Policy? American Psychologist, 64, 739-740. https://doi.org/10.1037/0003-066X.64.8.739

Stevenson, D. L., \& Baker, D. P. (1987). The Family-School Relation and the Child's School Performance. Child Development, 58, 1348-1357. https://doi.org/10.2307/1130626

Stewart, E. B. (2008). School Structural Characteristics, Student Effort, Peer Associations, and Parental Involvement: The Influence of School and Individual-Level Factor on Academic Achievement. Urban Education, 40, 179-204.

https://doi.org/10.1177/0013124507304167

Stormshak, E. A., Dishion, T. J., Light, J., \& Yasui, M. (2005). Implementing Family Centred Interventions within the Public Middle School: Linking Service Delivery to Change in Problem Behaviour. Journal of Abnormal Child Psychology, 33, 723-733. https://doi.org/10.1007/s10802-005-7650-6 
Vaden-Kiernan, N., McManus, J., \& Chapman, C. (2005). Parent and Family Involvement in Education: 2002-03. Washington, DC: National Center for Education Statistics; USDE Institute of Education Sciences.

Weiss, H. B., Mayer, E., Vaughan, M., Dearing, E., Hencke, R., Kreider, H., \& Pinto, K. (2003). Making It Work: Low Income Working Mothers' Involvement in Their Children's Education. American Educational Research Journal, 40, 879-901. https://doi.org/10.3102/00028312040004879

Winslow, E. B., Poloskov, E., Begay, R., \& Sandler, I. N. (2013). Theory-Based Strategies for Engaging Parents into Preventive Parenting Interventions: Results of a Randomized Experimental Study. Manuscript Submitted for Publication.

Wood, M. J., Ross-Kerr, J. C., \& Brink, P. J. (2006). Basic Steps in Planning Nursing Research: From Question to Proposal. Jones \& Bartlett Publishers.

Wright, T. (2009). Parent and Teacher Perceptions of Effective Parental Involvement. Doctoral Dissertation, Liberty University. 